DOI: $10.4274 /$ tjps.81300

\title{
Study of the tableting properties of MCR, a newly co-processed cellulose based direct compression excipient.
}

Running Title: MCR tabletting properties.

\section{Salah Aly}

Department of Pharmaceutics, AlJouf University, Sakaka, KSA.

INTRODUCTION: Co-processing technique has been utilized to develop excipients of improved or/and desired functionalities. Silicified MCC (Prosolve), cellactose and Avicel CE-15 are commercially available co-processed excipients which have improved flow and consolidation properties. One of the major limitations challenging co-processing technique is the fixed ratio of the excipients in a co-processed mixture which may not be an optimum choice for the active ingredient (s) and the dose per a formulation under development.

Trials were made to co-process excipients to manufacture direct compression MZ tablets.

The objective of this work was to co-process and evaluate the tableting properties of (MCR), a new cellulose-based tableted excipient produced from the slugs from the granules of $\mathrm{CMCC} / \mathrm{CRC}$. Metronidazole a model of non-freely flowing incompressible API was employed to evaluate MCR for the production of direct compression MZ tablets.

METHODS: Processing and evaluation of CMCC and CRC: CMCC and CRC were processed and evaluated for their physico-chemical properties.

Processing of MCR: MCR was produced by sifting the slugs of 4: $1 \mathrm{CMCC} / \mathrm{CRC}$ granules made with alcohol.. MCR was characterized and evaluated and used to compress $\mathrm{MZ}$ tablets.

Evaluation of MZ tablets: The produced MZ tablets were evaluated for their physicochemical properties

RESULTS: CMCC and CRC were successfully processed and the prepared MCR was successfully co-processed. The compressed MZ tablets were evaluated. Their mechanical properties and disintegration and dissolution behaviors were satisfactory. MCR was sensitive to magnesium stearate (MS) and moisture.

DISCUSSION AND CONCLUSION: MCR proved to be a direct compression excipient of adequate

tableting properties. Tablets of accepted mechanical properties and fast disintegrating and dissolving rates were produced. MCR is recommended to be applied as a direct compression excipient. It is unfortunately sensitive to MS and moisture which may limit its use 
Keywords: Micro-crystalline cellulose, Regenerated cellulose, MCR co-processing, MCR tableting properties of MCR.

\begin{abstract}
In this work, we aimed at co-processing and evaluating a new cellulose based direct compression tableting excipient (MCR) of improved functionalities by granulation and slugging from the locally extracted microcrystalline cellulose (CMCC) and regenerated cellulose (CRC). Model tablet formulations of metronidazole (MZ) as a model of nonfreely flowing and indirectly compressible API were designed to study the tableting properties of MCR. The result showed that the optimum concentration of CRC needed to produce excipient of accepted flow properties and high compression characteristics was $20 \% \mathrm{w} / \mathrm{w}$. MCR performed better than the parent components either singly or in a simple binary mixture. MZ tablets of enhanced mechanical properties and fast disintegrating and dissolving rates were compressed from MCR. The crushing strength $(\mathrm{H})$, and the disintegration rate constant $\left(\mathrm{k}_{\mathrm{d}}\right)$ increased from 3.76 to $11.08 \mathrm{~kg}$ and from 0.92 to $13.1 \mathrm{x}$ $10^{-3} \mathrm{~s}^{-1}$ for the tablets made with $50 \% \mathrm{w} / \mathrm{w}$ MCR, respectively. Both $\mathrm{H}$ and $\mathrm{k}_{\mathrm{d}}$ of a given $\mathrm{MZ}$ tablets batch were found to be functions of the total number of bonding sites $(\alpha)$ available in the excipient in the given batch.MCR was unfortunately sensitive against magnesium stearate (MS). The obtained result revealed that MCR is a successful complementary direct compression excipient.
\end{abstract}

Keywords: Micro-crystalline cellulose, Regenerated cellulose, MCR co-processing, MCR tableting properties of MCR.

Introduction

Co-processing technique has been utilized to develop excipients of improved or/and desired functionalities. The technique is defined as the concept of two or more excipients interacting physically at the sub-particle level to provide a synergy of functionality, improvements as well as masking the undesirable properties of individual excipients ${ }^{1}$. It rovides a broad platform for the manipulation of excipient functionality or particle engineering two or more existing excipients ${ }^{2,3}$. Silicified MCC (Prosolve), cellactose and Avicel CE-15 are commercially available co-processed excipients which have improved flow and consolidation properties ${ }^{4-10}$. Controlling particle size and particle-size distribution as co-processing means were used to produce excipients of improved flow with no need to add glidants ${ }^{5-7}$. However, cases of some co-processed powders of enhanced mechanical properties but having similar particle-size distribution of the parent powders were reported ${ }^{4-10}$. 
One of the major limitations challenging co-processing technique is the fixed ratio of the excipients in a co-processed mixture which may not be an optimum choice for the active ingredient (s) and the dose per a formulation under development ${ }^{11}$.

MCC tableting properties are close to optimal and has high degrees of compressibility, compactibility and high dilution potential. However, the bad flow properties and the sensitivity against MS are the main drawbacks of this excipient ${ }^{12}$. Cellulose regenerated (RC) from micro-fibril showed high physico-chemical and tableting properties ${ }^{13}$. Ahmad $^{14}$ reported that $\mathrm{RC}$ had glidant activity. Rojas et $\mathrm{al}^{15}$ found that $\mathrm{RC}$ has strong disintegration activity. Due to its large specific surface area, RC was successfully employed with olive oil to produce Dis-Lub-Tout, a newly co-processed tablet excipient of bi-functional activity $^{16,17}$.

$\mathrm{MZ}$ is an anti-microbial agent effective against anaerobic bacteria and protozoa. It is primarily used to treat bacterial vaginosis, pelvic inflammatory disease, wounds, intraabdominal infections, trichomoniasis, and infections caused by susceptible anaerobic organisms. Tablets are the commonly used dosage form of this drug ${ }^{18}$. Trials were made to co-process excipients to manufacture direct compression $\mathrm{MZ}$ tablets ${ }^{19,20}$.

Our objective in this work was to co-process and evaluate the tableting properties of MCR, a new cellulose-based tableted excipient produced from the granules of CMCC/CRC slugs. CMCC was locally extracted from the dried leaves and hollow stems of Common Reed plant (Phragmitesaustralis f. Gramineae) and was used to prepare CRC. Metronidazole a model of non-freely flowing incompressible API powder was employed to evaluate the tableting properties of MCR.

Materials and Methods

Materials

The dried leaves and hollow stems of the Common Reed plant were collected from different areas near to water resources and sewages in Assiut town (upper Egypt) at the harvest time (March -June). The analytical grade chemicals namely: absolute ethanol and sodium hydroxide pellets given by Krishna Chemicals, Mumbai-40078, Maharashtra and 98\% sulfuric acid obtained from Scharalab, S.L., Gato Prez, Spain, were used in this investigation, respectively. Metronidazole (Provizer Pharma, India), a model of non-freely flowing and in-compressible API, and magnesium stearate, the commonly used tablet lubricant (Scharalab, S.L., Gato Prez, Spain), were employed in this investigation. Methods 


\section{$\mathrm{CMCC}$ and $\mathrm{CRC}$ processing}

The collected plant material was thoroughly examined and the decayed parts were discarded. The selected parts were thoroughly washed, dried and ground using a suitable grinder. A $500 \mathrm{~g}$ sample of the powdered plant material was boiled in $2 \%$ sulfuric acid for $2 \mathrm{~h}$ to oxidize or/and destroy the lignin content in order to separate the cellulose fibers.

The acid and the acid soluble materials were filtered out and the collected solid materia was washed from the acid, neutralized and boiled in $12 \%$ of sodium hydroxide solution for $4 \mathrm{~h}$ to get rid of the lignin. The solid material was thoroughly washed from the alkali, neutralized and subjected to acid hydrolysis by boiling in 3 liters of $10 \%$ sulfuric acid solution for $3 \mathrm{~h}$ to produce CMCC. The yield was thoroughly washed from the acid, neutralized and bleached by boiling in 3 liters of $6 \%$ sodium hypochlorite for $2 \mathrm{~h}$. CMCC was thoroughly washed with distilled water, dried, pulverized and stored in a screw capped brown powder bottle till use. A $100 \mathrm{~g}$ sample of CMCC was suspended in $300 \mathrm{~mL}$ of $20 \%$ sodium hydroxide solution. The suspension was frozen at $-28^{\circ} \mathrm{C}$ for $12 \mathrm{~h}$ to dissolve the cellulose. The frozen cellulose solution was kept at room temperature $\left(25 \pm 2^{\circ}\right.$ C) for $18 \mathrm{~h}$. CRC precipitated by $1 \mathrm{~N}$ sulfuric acid solution was thoroughly washed with distilled water, neutralized, dried, pulverized and stored at room temperature $\left(25 \pm 2^{\circ} \mathrm{C}\right)$ in screw capped brown powder bottles till use.

IR characterization of cellulose powders

The IR spectra of authentic MCC sample and samples of CMCC and CRC powders were run using the technique described by Rojas et $\mathrm{al}^{21}$. In this technique, $1 \mathrm{mg}$ of a given sample was mixed with $100 \mathrm{mg}$ of $\mathrm{KBr}$ on an agate mortar. Pellets of this mixture were prepared on a portable press (CrushIR Digital Hydraulic press 161-1900, PIKE, NY, USA) at a dwell time of $5 \mathrm{~min}$ and at a force of $4540 \mathrm{~kg}$. The infrared spectra were run between 650 and $4000 \mathrm{~cm}^{-1}$ using a Perkin Elmer IR Spectrometer (Spectrum BX, PerKin Elmer, CA, USA) equipped with the Ommic software (Nicolet Corp., Madison, WI, USA). The resolution, interval length were 16 and $2 \mathrm{~cm}^{-1}$, and the number of scans employed was $16 \mathrm{~cm}^{-1}$, respectively.

Physical properties of Cellulose and MZ powders

Particle shape and effective mean particle diameter

The shapes of CMCC and CRC particles were characterized by SEM (BM-180, Bo-eco, GmbH, Frankfurt, Germany) attached to a digital camera (S8000fd, Fujifilm Corp., Japan). A suitable volume of the given powder sample was mounted in the specimen stub of the SEM for micro-photographing (no sputtering was noticed). The effective mean 
diameters of CMCC and MZ particles were determined by sieving technique using a set of stainless steel sieves (Fritsch, GmbH, FRG) arranged in descending order as described early ${ }^{16}$. The effective mean diameter of CRC particles was determined using a size analyzer (Brookhaven Instruments Corp., 750 Blue Point Holtsville, NY11742, USA) equipped with default particle sizing software program (ver. 3.74). A sample of dilute $\mathrm{CRC} /$ water suspension was used for the test. The refractive index of the sample was 1.3 the beam angle and the wave length were $90^{\circ}$ and $678 \mathrm{~nm}$, respectively.

Flow properties, density and moisture content determinations of powders Funnel technique was employed to determine the volumetric flow rates and repose angles of the powders under investigation. The apparent density, $\rho$, of a given powder was determined using the liquid displacement technique. The bulk, $\rho$ в, and tap, $\rho$, densities and packing fraction, $\rho f$, were determined using the early reported techniques ${ }^{16}$, respectively. The mean of five determinations of each experiment was calculated and taken as the determined value. The moisture content (dry weight basis) was determined by drying technique as described earlier ${ }^{16}$.

Moisture sorption isotherm study Moisture sorption isotherm exhibited by MCR was studied and compared with that of the parent components. For the test, accurately weighed $1 \mathrm{~g}$ samples of MCR CRC and $\mathrm{CMCC}$ and were stored on shelf at ambient condition $\left(25 \pm 2{ }^{\circ} \mathrm{C}-\mathrm{RH} 45 \pm 2 \%\right)$, and at $40^{\circ} \mathrm{C}-\mathrm{RH} 75 \%$, respectively. The RH\% conditions was achieved by using a saturated solution sodium chloride. Gallenkamp humidity oven (Gallenkamp, London, United Kingdom) was employed for the test. At a predetermined time interval, a sample of a stored powder was evaluated for the amount of the adsorbed moisture (dry weight basis). Swelling index (SI) and hydration capacity (HC) determinations SI of a given cellulose powder was determined as follows ${ }^{16}$ : An accurately weighed $1 \mathrm{~g}$ sample of the given cellulose powder was suspended in $25 \mathrm{~mL}$ distilled water and vigorously shaken at $10 \mathrm{~min}$. time interval for $1 \mathrm{~h}$. The suspension was equilibrated for 24 $\mathrm{h}$ and the volume occupied by the powder under the test was precisely determined. SI was calculated from: $\mathrm{SI}=\mathrm{v}-\mathrm{v}^{\mathrm{o}} / \mathrm{v}^{\mathrm{o}} \times 100$ where $\mathrm{v}$ and $\mathrm{v}^{\mathrm{o}}$ stand for the volumes of the test powder sample before and after the test, respectively. The mean of such 5 determinations was taken as SI of the given powder. HC of a given cellulose powder was measured as follows: A $2 \mathrm{~g}$ sample of a given powders was suspended in $10 \mathrm{~mL}$ of distilled water in a centrifuge tube and shaken intermittently for $2 \mathrm{~h}$. The tube was left to stand for $30 \mathrm{~min}$. and centrifuged at $3000 \mathrm{rpm}$ for $10 \mathrm{~min}$. HC was calculated from the weight (w) of the 
powder before the test as : $\mathrm{HC}=\mathrm{w}-2 / 2 \times 100$ as reported earlier ${ }^{16}$. The mean of such 5 determinations was taken as $\mathrm{HC}$ of the given powder

MCR Co-processing

Binary mixtures of $\mathrm{CMCC} / \mathrm{CRC}$ containing varying portions of $\mathrm{CRC}$ were prepared using a laboratory assembled $0.75 \mathrm{~kg}$ capacity drum mixer. The preliminary tests carried out showed that the optimum concentration of CRC needed to produce a mixture of improyed flow properties (flow rate and repose angle) was $20 \% \mathrm{w} / \mathrm{w}$ ( 1 part of CRC to 4 parts of $\mathrm{CMCC})$. A batch of $500 \mathrm{~g}$ of this physical mixture (PM) was prepared and employed to co-process MCR as follows: The mixture was placed into a porcelain mortar of suitable capacity and kneaded with a sufficient volume $(400 \mathrm{~mL})$ of absolute ethanol. The damp mass was forced through a $350 \mu \mathrm{m}$ sieve mesh and the resulted granules were dried at $50^{\circ}$ $\mathrm{C}$ for $6 \mathrm{~h}$ using a Binder oven (FRG). The granules were placed on a tray and put into the oven. The obtained dried granules were equilibrated at room conditions for $24 \mathrm{~h}$. Although FTIR technique to test for the residual alcohol in pharmaceutical solids is limited by the high detection limit (above $100 \mathrm{ppm}$ ), it was decided to employ it using the above mentioned method and equipment to test for the residual alcohol in the prepared granules since the allowed limit for residual ethanol in pharmaceutical solids is high $(5000 \mathrm{ppm})^{23}$. The IR spectrum run showed that the produced granules were alcohol free. The produced granules were compressed into large slugs using a single punch tableting machine (F3, Manesty Machines Ltd., Liverpool, UK). The machine settings were adjusted to produce slugs of $5 \mathrm{~g}$ mean weight and of the highest tensile strength that could be achieved. The machine was manually run and the surfaces of the punches were frequently cleaned from sticky powder. The produced slugs were crushed using a laboratory oscillating granulator and sifted through a $90 \mu \mathrm{m}$ sieve mesh. The obtained MCR powder was stored at room temperature $\left(25 \pm 2^{\circ} \mathrm{C}\right)$ in a screw capped wide mouth brown powder bottle till use. Characterization of MCR

The flow rate, repose angle, packing fraction, $\rho f$, and density (apparent, bulk and tap) of MCR were determined using the above mentioned techniques. The moisture content, swelling index and hydration capacity determinations were carried out employing the above mentioned methods ${ }^{16}$. The mean of 5 determinations of each experiment was calculated and taken as the determined value. Formulation, compression and evaluation of MZ tablets Simple mixing technique was adopted to prepare MZ tablets. Tablets batches formulated with $20,30,50$, and $75 \% \mathrm{w} / \mathrm{w}$ of a given excipient were prepared. Lubrication was carried 
out just before compression. Tablets were compressed using a Manesty single punch tableting machine fitted to flat faced punches adopting the modified compression technique ${ }^{17}$. The machine was adjusted to compress tablets of $250 \pm 0.05 \mathrm{mg}$ mean weight, $9.0 \pm 0.02 \mathrm{~mm}$ mean diameter and of the highest crushing strength, $\mathrm{H}$, and lowest friability, $\mathrm{F}$, levels that could be achieved from the batch formulated with $75 \% \mathrm{w} / \mathrm{w}$ (the highest concentration) of a given excipient. The machine settings were kept constant throughout compressing the rest batches formulated with the lower concentration of the given excipient. Altogether 1000 tablets were compressed from each batch. The machine settings were re-adjusted whenever formulations of a new excipient were compressed. The produced tablets were evaluated for the uniformity of weight and thickness, mechanical properties, $(\mathrm{H}, \mathrm{F}$ and porosity, $\varepsilon)$ and the disintegration times $(\mathrm{Dt})$. Determination of $\mathrm{H}, \mathcal{E}$ and $\mathrm{F}$ of $\mathrm{MZ}$ tablets

A digital recording Erweka THB-28 hardness tester (Erweka, Darmstadt, Germany) was used to determine the mean crushing strength of a given MZ tablet batch. For the test, a sample of 10 tablets was randomly collected from a given batch. The tablets were individually tested for the crushing strength and the mean was calculated and taken as the crushing strength of the given batch. $\varepsilon$ of a given tablet batch was calculated from the relation: $\varepsilon=\left(\mathrm{Vt}_{\mathrm{t}}-\mathrm{V}_{\mathrm{o}}\right) / \mathrm{vt}$, where $\mathrm{vt}$ and $\mathrm{vo}_{\mathrm{o}}$ equal the tablet volume and the true volume(s) of the powder (s) in the given tablet batch. The mean of five calculations was considered as the porosity of the given tablet batch.F of a MZ tablet batch was determined using a Roch friabilator (Erweka, Darmstadt, Germany). A sample of 20 tablets randomly collected from the given batch was brushed free from adhering dust and precisely weighed and placed into the friabilator drum. The apparatus was adjusted to revolve at $25 \mathrm{rpm}$ for 4 min. At the end of the test, the tablets were re-brushed and precisely re-weighed. The percent loss in weight was calculated as $\mathrm{F}$ of the tablets. The mean of such five determinations was used as $\mathrm{F}$ of the tested $\mathrm{MZ}$ tablet batch.

Determination of Dt and $\mathrm{k}_{\mathrm{d}}$ of tablets

Neutral buffer solution of $\mathrm{pH} 7.2$ was employed to carry out the disintegration and dissolution rate determination tests. This is to exclude the effect of $\mathrm{pH}$ of the medium on the disintegration and dissolution rates.

Determination of Dt of tablets

The USP disintegration test apparatus (ZT 220, Erweka, Darmstadt, Germany) was employed to determine the disintegration times of the compressed tablets. A sample of 6 tablets randomly selected from a given MZ batch was used in this investigation. Each 
tablet was accurately weighed and placed into a disintegration tube of the apparatus. The time when the fragments of the tested tablet completely passed the screen mesh at the base of the disintegration tube was recorded as the Dt. The mean of such 10 determinations was calculated as Dt of a given MZ batch.

Study of dissolution behavior of MZ tablets

A rotating basket USP dissolution rate test apparatus (model DT-D, Erweka, Germany) was employed to determine the dissolution rate of $\mathrm{MZ}$ tablets in $900 \mathrm{~mL}$ of $7.2 \mathrm{buffer}$ solution. All the USP requirements for dissolution rate test were kept constant. The test was carried out at $37 \pm 0.5^{\circ} \mathrm{C}$. A sample of 6 tablets randomly collected from a given batch was employed to carry out the test. For the test, one tablet was precisely weighed and placed into the basket of the apparatus. The revolution of the basket was adjusted to $100 \mathrm{rpm}$. At a predetermined time interval accommodated with the disintegration time of the batch under the test, a $5 \mathrm{~mL}$ aliquot sample was withdrawn from the dissolution chamber and was immediately substituted by equal volume of freshly prepared dissolution medium maintained at $37 \pm 0.5^{\circ} \mathrm{C}$. The amount of $\mathrm{MZ}$ in the withdrawn sample was determined spectrophotometrically at $340 \mathrm{~nm}$ with a reference to a calibration curve constructed using a pure MZ sample as used in formulation. The mean of such 6 determinations was taken as a point on the dissolution curve.

Study of MCR sensitivity against MS

The effects of lubrication with 1.0,1.5 and $3 \% \mathrm{w} / \mathrm{w}$ of MS on H, F and Dt of MZ tablets batch formulated with $75 \% \mathrm{w} / \mathrm{w}$ of MCR were studied.

\section{RSEULTS}

IR characterization of $\mathrm{CMCC}$ and $\mathrm{CRC}$

The IR spectra of MCC and CRC powders given in Figure 1 show the following characteristic vibration peaks of cellulose: $3445 / \mathrm{cm}$ corresponding to intra-molecular $\mathrm{OH}$ stretching, including hydrogen bonds; $2898 / \mathrm{cm}$ due to $\mathrm{CH}$ and $\mathrm{CH} 2$ stretching; 1650/cm corresponding to $\mathrm{OH}$ from absorbed water; $1430 / \mathrm{cm}$ due to $\mathrm{CH} 2$ symmetric bending; $1375 / \mathrm{cm}$ due to $\mathrm{CH}$ bending; $1330 / \mathrm{cm}$ due to $\mathrm{OH}$ in-plane bending; $1161 / \mathrm{cm}$ due to $\mathrm{C}-\mathrm{O}-$ $C$ asymmetric stretching ( $\beta$-glucosidic linkage); 1061/cm due to $\mathrm{C}-\mathrm{O} / \mathrm{C}-\mathrm{C}$ stretching; and $898 / \mathrm{cm}$ corresponding to the asymmetric (rocking) C-1 ( $\beta$-glycosidic linkage) out-of-plane stretching vibrations. No new peaks were seen in the spectra suggesting that CMCC and CRC are chemically similar to microcrystalline cellulose.

Physical properties of Cellulose and MZ powders 
Figure 2 shows that CMCC and CRC particles were morphologically similar. They were elongated and amorphous particles. Table 1 shows that their effective mean particle diameters were 90 and $3 \mu \mathrm{m}$, respectively. Such elongated particles have a tendency to intermesh and create internal resistance against the flow of the powder ${ }^{12}$.

Table 1 also shows that the moisture contents, SI and $\mathrm{HC}$ values of the studied powders were high. Figure 3 shows that the investigated excipients exhibited more or less equal moisture sorption isotherm patterns.

Physical properties of MZ tablets.

Uniformity of MZ tablets

The data in Table 2 show that more uniform MZ tablets were compressed with CRC followed by MCR and CMCC, respectively. The uniformity generally increased (estimated by the decrease in \% CV) as the concentration of the excipient in an examined tablets batch increased. PM produced non-uniform tablets due to the segregation observed during compression.

Mechanical properties of MZ tablets

Compressibility and compactibility of excipients.

The yield value obtained from Heckel plot ${ }^{24}$ and the energy consumption during compression determined from force-displacement $\mathrm{plot}^{25}$ are usually parameters involved to measure powders compressibility. In this investigation since a given tablet formulation was compressed under confined machine settings, it follows that the number of sites available for bonding in a given concentration of an excipient in a formulation is the solely the working parameter. In other words, the mechanical properties of the excipient in the given formulation are excipient concentration dependent factors. Excipient concentrationdisplacement plot was constructed (see Figure 4a) and the area under the curve (AUC) was taken as a parameter indicative of the compressibility of a studied excipient. The compressibility index, $\mathrm{k}_{\varepsilon}$, of an excipient in a given formulation was calculated from the relation:

$\varepsilon=\varepsilon^{0}$ exp. $-\mathrm{k}_{\varepsilon} \mathrm{C}$

where $\varepsilon$ and $\varepsilon^{0}$ stand for the porosity fractions for compacts made from a given excipient and the lubricated drug only (control tablets batch)(see Figure b), respectively. On the other hand, Figure $4 \mathrm{c}$ was constructed to calculate the compactibility index, $\mathrm{k}_{\mathrm{p}}$, of the given excipient. It was calculated from the relation: 
$\mathrm{H}=\mathrm{H}^{\mathrm{o}}$ exp. $\mathrm{k}_{\mathrm{p}} \mathrm{C}$

where $\mathrm{H}$ and $\mathrm{H}^{\circ}$ represent the crushing strengths of the batches made with the given excipient and the control tablets batch, respectively. The data given in Table 3 show that more compressed formulation were produced by MCR followed by $\mathrm{CRC}, \mathrm{CMCC}$ and PM, respectively.

Disintegration and dissolution behaviors of MZ tablets

Figure 5 shows that the disintegration rate constant, $\mathrm{k}_{\mathrm{d}}$, generally decreased as the excipient concentration, $\mathrm{C}$, increased in a given tablet batch and the relation:

$\mathrm{kd}_{\mathrm{d}}=\mathrm{kd}^{\mathrm{o}} \exp \cdot \mathrm{xC}^{\mathrm{C}}$

where $x$ is the disintegration activity of the excipient in a given formulation worked. The constants $\mathrm{k}_{\mathrm{d}} \& \mathrm{kd}_{\mathrm{d}}{ }^{\mathrm{a}}$ stand for the disintegration rate constants of the batches made with a given excipient and the control tablets batch, respectively. The data in Figure 6 discloses that $\mathrm{k} \varepsilon$ and $x$ of a given excipient were functions of $\mathrm{k}_{\mathrm{p}}$ of the given excipient. In other words, the compressibility and the disintegration activity of an excipient are excipient compactibility depend parameters. Figure 7 shows that tablets made from CR and MCR dissolved in more or less equal rates which are faster than the tablets made from CMCC. MCR sensitivity against MS

Lubrication with MS generally produced less hard and more friable and slower disintegrating tablets. These adverse effects increased as the concentration of MS in a tested tablet batch increased. The changes in H, F and Dt of tablets lubricated with $3 \%$ w/w MS are given in Table 4.

Discussion and conclusion

The IR spectra in Figure1 indicate that the tested powders are chemically similar. No new peaks suggesting the development of new materials were seen. The differences in the shape and intensity of the peaks were due to the different crystal lattice of the tested powders.

CMCC and CRC particles were elongated and amorphous. Such particles have a tendency to intermesh and create a resistance (due to inter-particle friction) against the flow of the bulk powder ${ }^{12-15}$. This explains why CMCC is not freely flowing powder $\left(0.21 \mathrm{~g} \mathrm{~s}^{-1}\right)$. Although the Hausner ratio $(h)$ and the \% compressibility determined for MCR were 1.6 
and 38, MCR showed improved flow rate, respectively. This is explained as follows: It should be clear in mind that the Huasner ratio and Carr's index are empirically derived parameters obtained with no scientific basis and this is why they fail in many cases to give a strong base and sharp judgment about powder flow. The improved flow properties of MCR may be due to the glidant effect of CRC. It seems that CRC reduced the interparticle friction of the powder and improve its flow.

Since CRC had a large specific surface area wherein a large $\alpha$ is available, it is expected that MCR has improved compression and compaction properties and generates larger AUC, $\mathrm{k} \varepsilon$ and $\mathrm{k}_{\mathrm{p}}$ values. $\alpha$ of a given excipient may be calculated as:

$\alpha=\mathrm{L} . \mathrm{kp}_{\mathrm{p}} \mathrm{Wt} . \Sigma\left(\mathrm{r}_{\mathrm{i}} / \mathrm{MW}_{\mathrm{i}}\right)$

where L, wt., $\mathrm{r}_{i}$ and MWi stand for Avogadro's number $\left(6.022 \times 10^{23}\right)$, the weight of the excipient in a batch, the fraction of a parent excipient used in co-processing and its molecular weight, respectively. CRC and MCR almost showed the same level of disintegration activity and they generated smaller $x$ values as shown in Table 3 . CRC followed by MCR produced fast dissolving tablets. This is due to the powerful disintegration effect of $\mathrm{CRC}^{15}$. Incorporating a powerful disintegrant in formulating tablets would contribute to the bio-response of the tablets ${ }^{26}$. MCR was unfortunately sensitive against MS.

In response to the increasing demand of in-expensive and multifunctional excipients with minimum risk to the products, MCR was engineered from MCC and regenerated cellulose. MCR has high functionality in terms of flow, compression, good binding properties and strong disintegrating activity. However, it is sensitive against magnesium stearate and exhibits high moisture up-take and therefore it is recommend as a complementary direct compression excipient

Acknowlegement

The author is grateful to Prof. Dr. J. Rojas for the technical assistance.

\section{REFERENCES}

1. Reimerdes D. The near future of tablet excipients. Manufacturing Chemist 1993; 64: 14-15.

2. Saha S, Shahiwala AF. Multifunctional co-processed excipients for improved tabletting performance. Expert Opin Drug Deliv 2009;6:197-208. 
3. Mirani AG, Patankar SP, Borole VS, Pawar AS, Kadam VJ. Direct compression high functionality excipient using co-processing technique: A brief review. Curr Drug Deliv 2011;8:426-435.

4. Philip F, Bonaventurea BAM, Tiwaladeb A, Okpakoc LC, Attama AA. Novel multifunctional pharmaceutical excipients derived from microcrystalline cellulose-starch micro particulate composites prepared by compatibilized reactive polymer blending. Int $\mathrm{J}$ Pharm 2010;388:159-167.

5. Gonnissen Y, Remon JP, Vervaet C. Development of directly compressible powders via co-spray drying. Eur J Pharm BioPharm 2007;67:220-226.

6. Gohel MC, Jogani PD. Exploration of melt granulation technique for the development of co-processed directly compressible adjuvant containing lactose and microcrystalline cellulose. Pharm Dev Technol 2003;8:175-185.

7. Sherwood BE, Becker JW. A New class of high functionality excipients: silicified microcrystalline cellulose. Pharm Technol 1998;22:78-88.

8. Nachaegari SK, Bansal AK. Co-processed excipient for solid dosage forms. Pharm Techol 2004;28:52-64.

9. York P. Crystal engineering and particle design for the powder compaction process. Drug Dev Ind Pharm 1992;18:677-721.

10. Gohel MC, Jogani PD. A review of co-processed directly compressible excipients. J Pharm Pharmaceut Sci 2005;8:76-93.

11. Reier CE, Shangraw RF, Microcrystalline cellulose in tabletting. J Pharm Sci 1966; 55:10-15.

12. Bolhuis GK, Zuurman k., Maarschalk VV. Effect of magnesium stearate on bonding and porosity expansion of tablets produced from materials with different consolidation properties. Int J Pharm 1999; 179:107-115.

13. V. Kumar, Powdered micro-fibrillated cellulose, US Patent 6,821,531 B2, 2004.

14. Ahmad FAS. Evaluation of regenerated cellulose as a glidant for Common Reed cellulose. IJPJ's J Pharm. \& Cosmet 2013;3:18-22.

15. Rojas J, López A, Gamboa Y, González C, Montoya F. Assessment of processing and polymorphic form effect on the powder and tableting properties of microcrystalline celluloses I and II. Chem Pharm Bull 2011;59:603-607.

16. Aly SAS. Evaluation of Dis-Lub-Tout, a new co-processed tabletting excipient 1. Physico-chemical properties. J Drug Del Sci Tech 2014;24:503-506.

17. Aly SAS. Evaluation of Dis-Lub-Tout, a new co-processed tabletting excipient 2. Lubricant property. J Drug Del Sci Tech 2014;24:678-683. 
18. Phillips MA, Samuel SL. Chemotherapy of protozoa infections. In: Brunton LL; Lazo JS; Parker KL, eds. The Pharmacological Basis of Therapeutics. $10^{\text {th }}$ ed., New York: MCGraw-Hill Medical Publishing Division; 2006, p.1049-1069.

19. Chime SA, Onyishi VI, Onyechi JO. Co-processed metronidazole granules for tabletting: Formulation and in vitro evaluation. Int J Pharm Sci Rev 2013;22:13-17.

20. Adebowale BO, Oluwatomi O, Gbenga BL. Compressional properties of metronidazole tablet formulations containing aloe vera as binding agent. Int J Pharm Pharm Sci 2014;10:261-264.

21. Rojas J, Lopez A, Guisao S, Ortiz C. Evaluation of several microcrystalline celluloses obtained from agricultural by-products. J Adv Pharm Tech Res 2011;2:144-150.

22. Aly SAS. Detachment and recovery index: A new parameter measuring powder Compressibility. J Adv Phrm Tech Res 2010;1:406-414.

23. Hu C, Liu Y. Quality Control in Pharmaceuticals: Residual Solvents Testing and Analysis. In: Akyar I, eds. Wide Spectra of Quality Control. INTECH; 2011 p.183-210. URL: http://www.intechopen.com/books/wide-spectra-of-quality-control.

24. Heckel RW. Density/pressure relationship in powder compaction. Trans Metall Soc AIME 1961;22:1671-1675.

25. Antikainen O, Yliruusi J. Determining the compression behaviour of pharmaceutical powders from the force-distance compression profile. Inter J Pharm 2003;61:252-253.

26. Kanher PR. Lubricants in pharmaceutical solid dosage forms with special emphasis on magnesium stearate. World J Pharm Sci 2017; Sep. in Press. 
Table1: Physical properties of metronidazole and the investigated cellulose powders.

\begin{tabular}{|c|c|c|c|c|c|c|c|c|c|c|c|c|c|}
\hline $\begin{array}{l}\text { Drug } \\
\& \\
\text { excip. } \\
\text { used }\end{array}$ & $\begin{array}{l}\text { Mean } \\
\text { part } \\
\text { diam } \\
\mu \mathrm{m}\end{array}$ & $\begin{array}{l}\text { Flow } \\
\text { rate } \\
\text { g s }^{-1} \\
\pm \\
\text { SD }\end{array}$ & $\begin{array}{l}\text { Rep. } \\
\text { angle } \\
\text { deg. } \\
\pm \\
\text { SD }\end{array}$ & $\begin{array}{l}\quad \text { Den } \\
\text { App } \\
\pm \\
\text { SD }\end{array}$ & $\begin{array}{l}\text { Isity(g.c } \\
\text { bulk } \\
\pm \\
\text { SD }\end{array}$ & $\begin{array}{c}\mathbf{m}^{-3} \text { ) } \\
\text { tap } \\
\pm \\
\text { SD }\end{array}$ & $\begin{array}{l}\text { Moist. } \\
\text { cont. } \\
\% \text { w/w } \\
\pm \\
\text { SD }\end{array}$ & $\begin{array}{l}\text { Pack. } \\
\text { fract., } \\
\rho f \% \\
\text { calcula } \\
\text {-ted }\end{array}$ & $\begin{array}{c}\text { Com } \\
\text { press } \\
\text { ibility } \\
\text { index } \\
\quad \%\end{array}$ & $\begin{array}{l}\text { Haus } \\
\text {-ner } \\
\text { ratio } \\
\text { (h) }\end{array}$ & $\begin{array}{l}\text { surf } \\
\text { ea }\end{array}$ & $\begin{array}{l}\text { hyd. } \\
\text { cap. } \\
\text { g/g } \\
\pm \\
\text { SD }\end{array}$ & $\begin{array}{l}\text { swell. } \\
\text { index } \\
\text { g/g } \\
\pm \\
\text { SD }\end{array}$ \\
\hline MZ & 90 & $\begin{array}{l}0.11 \\
(0.03)\end{array}$ & $\begin{array}{l}40 \\
(2.11)\end{array}$ & $\begin{array}{l}1.52 \\
(0.34)\end{array}$ & $\begin{array}{c}0.90 \\
(0.11)\end{array}$ & $\begin{array}{c}1.30 \\
(0.31)\end{array}$ & $\begin{array}{l}3.50 \\
(0.34)\end{array}$ & 59 & & & & - & - \\
\hline СМСС & 90 & $\begin{array}{l}0.21 \\
(0.10)\end{array}$ & $\begin{array}{l}42 \\
(4.30)\end{array}$ & $\begin{array}{l}1.50 \\
(0.76)\end{array}$ & $\begin{array}{l}0.91 \\
(0.18)\end{array}$ & $\begin{array}{l}1.32 \\
(0.52)\end{array}$ & $\begin{array}{l}4.76 \\
(0.19)\end{array}$ & 61 & & & $\begin{array}{r}8.2 \\
-\quad\end{array}$ & $\begin{array}{l}2.31 \\
(0.41)\end{array}$ & $\begin{array}{l}1.50 \\
(0.33)\end{array}$ \\
\hline CRC & 03 & $\begin{array}{l}1.20 \\
(0.05)\end{array}$ & $\begin{array}{l}38 \\
(6.70)\end{array}$ & $\begin{array}{l}1.52 \\
(0.32)\end{array}$ & $\begin{array}{l}0.28 \\
(0.27)\end{array}$ & $\begin{array}{c}0.41 \\
(0.13)\end{array}$ & $\begin{array}{l}6.4 \\
(0.08)\end{array}$ & & & & $\begin{array}{l}132.0 \\
-\end{array}$ & $\begin{array}{l}2.87 \\
(0.65)\end{array}$ & $\begin{array}{l}1.75 \\
(0.53)\end{array}$ \\
\hline MCR & - & $\begin{array}{l}0.94 \\
(0.09)\end{array}$ & $\begin{array}{l}38 \\
(3.92)\end{array}$ & $\begin{array}{l}1.62 \\
(0.18)\end{array}$ & $\begin{array}{l}0.78 \\
(0.20)\end{array}$ & $\begin{array}{c}1.25 \\
(0.16)\end{array}$ & & & & 1.60 & - & $\begin{array}{l}2.67 \\
(0.34)\end{array}$ & $\begin{array}{l}1.73 \\
(0.22)\end{array}$ \\
\hline PM & - & $\begin{array}{l}0.52 \\
(0.06)\end{array}$ & $\begin{array}{l}40 \\
(2.43)\end{array}$ & $\begin{array}{r}1.65 \\
(0.25)\end{array}$ & $\begin{array}{r}0.71 \\
(0.31)\end{array}$ & $\begin{array}{c}1.28 \\
(0.11)\end{array}$ & $\begin{array}{l}5.11 \\
(1.10)\end{array}$ & & 45 & 1.64 & - & $\begin{array}{l}2.61 \\
(0.24)\end{array}$ & $\begin{array}{l}1.66 \\
(0.19)\end{array}$ \\
\hline
\end{tabular}




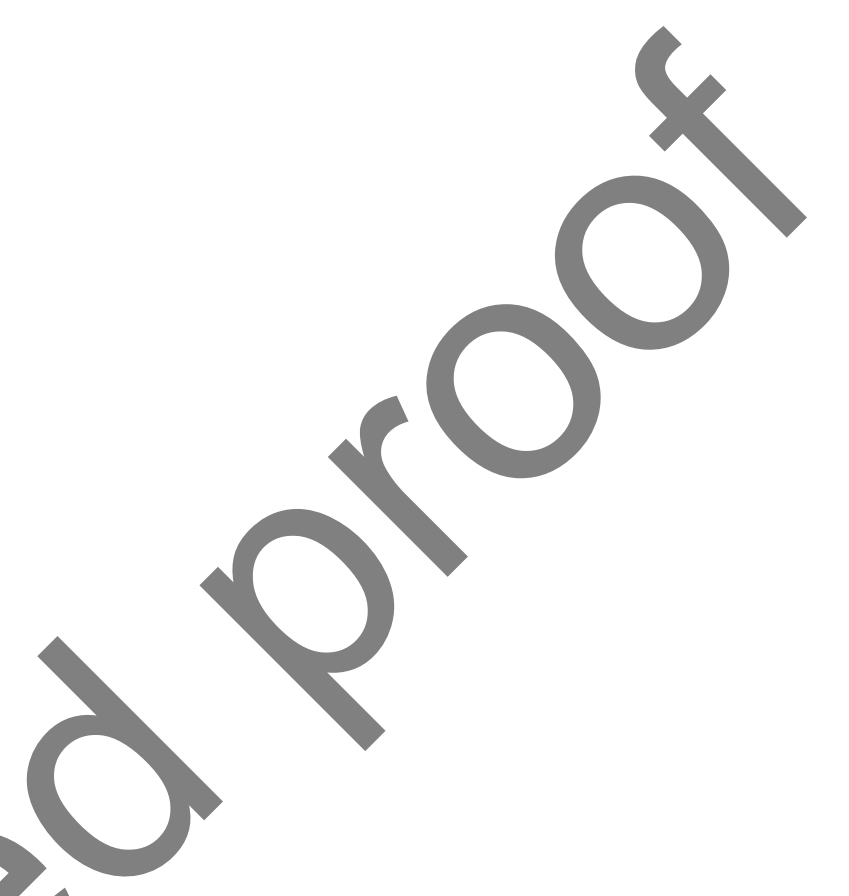

Table 2: Physical properties of metronidazole tablets compressed directly with increasing concentrations of the named cellulose excipients.

\begin{tabular}{|c|c|c|c|c|c|c|c|}
\hline \multirow{3}{*}{$\begin{array}{l}\text { Excip- } \\
\text { ient } \\
\text { used } \\
\text { CMCC }\end{array}$} & \multirow{2}{*}{$\begin{array}{l}\text { Conc. } \\
\% \\
\mathbf{w} / \mathbf{w}\end{array}$} & \multirow{2}{*}{\multicolumn{2}{|c|}{ Mean }} & \multicolumn{2}{|c|}{$\begin{array}{l}\text { Thickness } \\
\text { (cm) }\end{array}$} & \multicolumn{2}{|c|}{$\begin{array}{l}\text { Friability, } \\
(\text { Loss\%w/w) }\end{array}$} \\
\hline & & & & Mean & $\begin{array}{l}\mathrm{CV} \\
\%\end{array}$ & Mean & $\begin{array}{l}\mathrm{CV} \\
\%\end{array}$ \\
\hline & 20 & & & 0.360 & 2.4 & 0.23 & 11.5 \\
\hline & 30 & 0.2533 & 12.2 & 0.351 & 5.5 & 0.37 & 14.2 \\
\hline & & 0.2603 & 16.4 & 0.343 & 3.2 & 0.41 & 3.1 \\
\hline & & 0.2696 & 8.2 & 0.336 & 2.1 & 0.49 & 1.1 \\
\hline & & 0.2521 & 2.2 & 0.356 & 1.6 & 0.18 & 8.1 \\
\hline & 50 & 0.2576 & 6.1 & 0.341 & 12.4 & 0.25 & 3.8 \\
\hline & & 0.2651 & 4.9 & 0.332 & 12.4 & 0.31 & 1.1 \\
\hline & & 0.2708 & 1.5 & 0.326 & 12.4 & 0.38 & 6.1 \\
\hline CRC & 20 & 0.2517 & 4.7 & 0.362 & 6.4 & 0.18 & 6.3 \\
\hline & 30 & 0.2571 & 3.2 & 0.357 & 9.2 & 0.31 & 3.4 \\
\hline & 50 & 0.2599 & 1.3 & 0.352 & 12.6 & 0.39 & 7.2 \\
\hline & 75 & 0.2601 & 0.8 & 0.330 & 14.8 & 0.48 & 1.9 \\
\hline PM & 20 & 0.2500 & 49.2 & 0.359 & 11.6 & 0.43 & 9.8 \\
\hline & 30 & 0.2276 & 36.1 & 0.211 & 12.4 & 0.95 & 3.8 \\
\hline & 50 & 0.2151 & 14.9 & 0.212 & 12.4 & 1.91 & 1.1 \\
\hline & 75 & 0.2208 & 35.5 & 0.216 & 12.4 & 4.38 & 6.1 \\
\hline
\end{tabular}




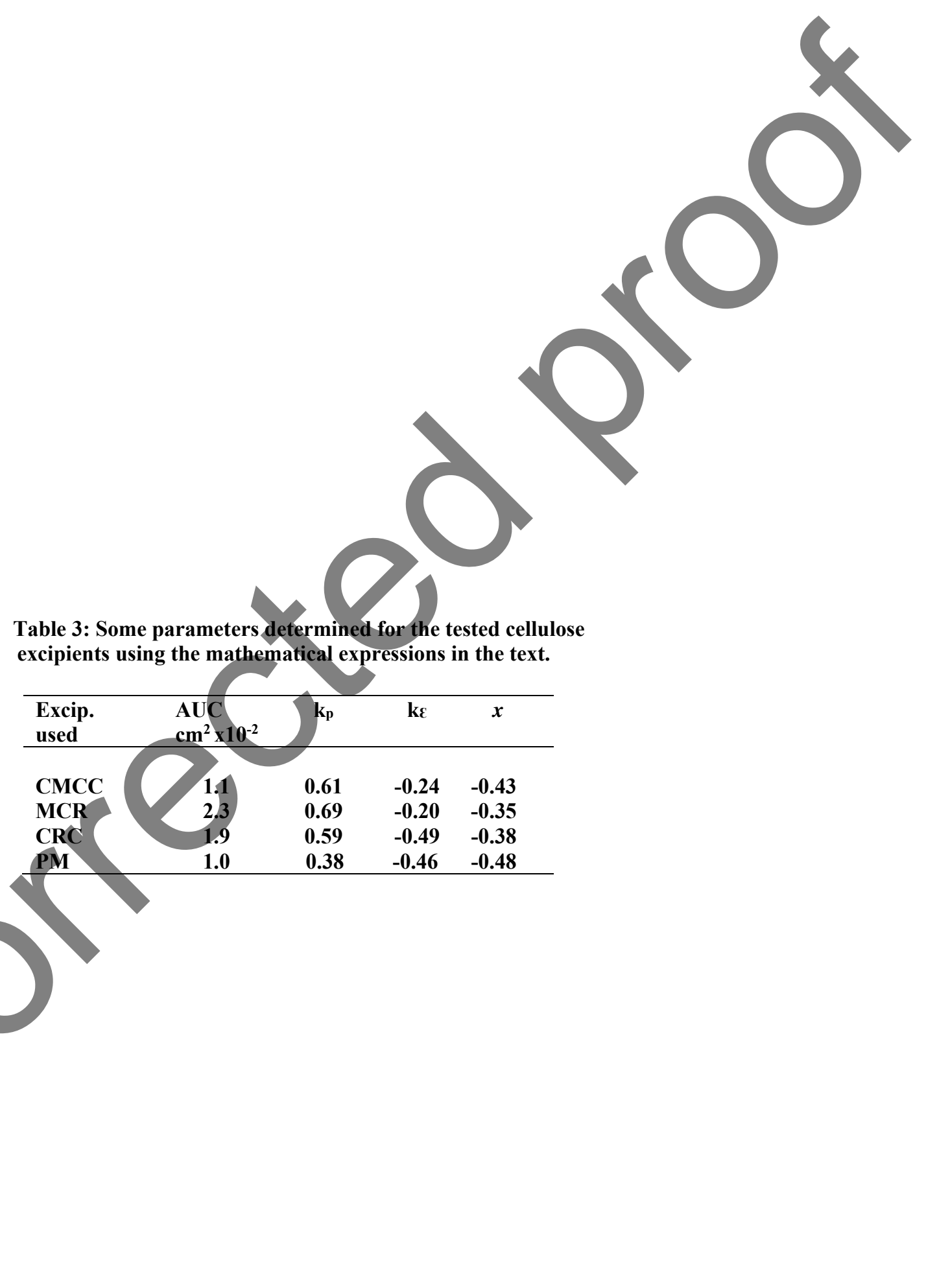


Table 4: \% Change in some physico-chemical properties of tablets compressed with the named excipients and lubricated with different concentrations of MS.

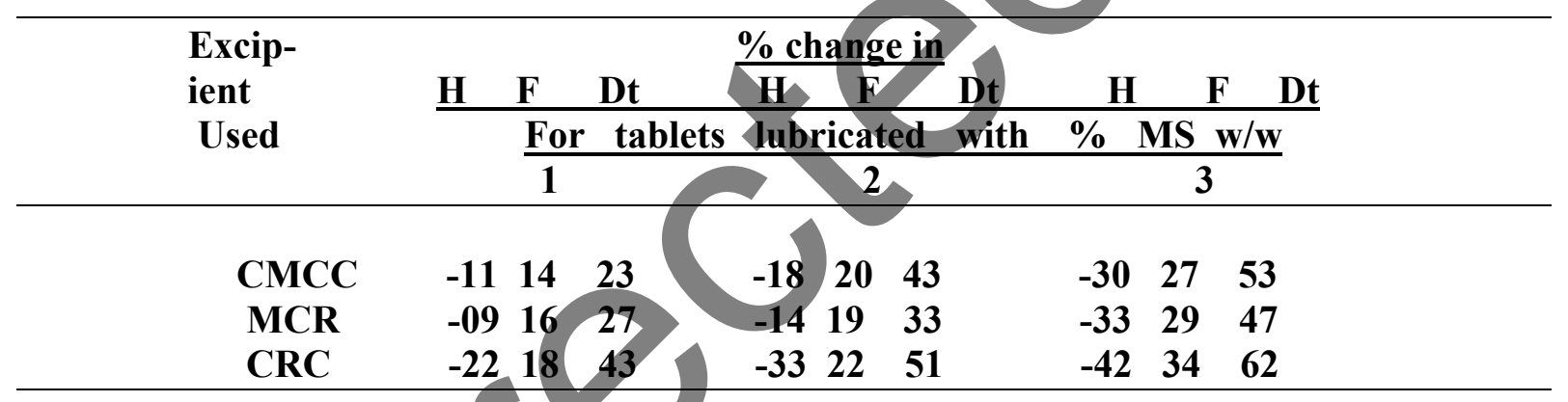


Figure 1

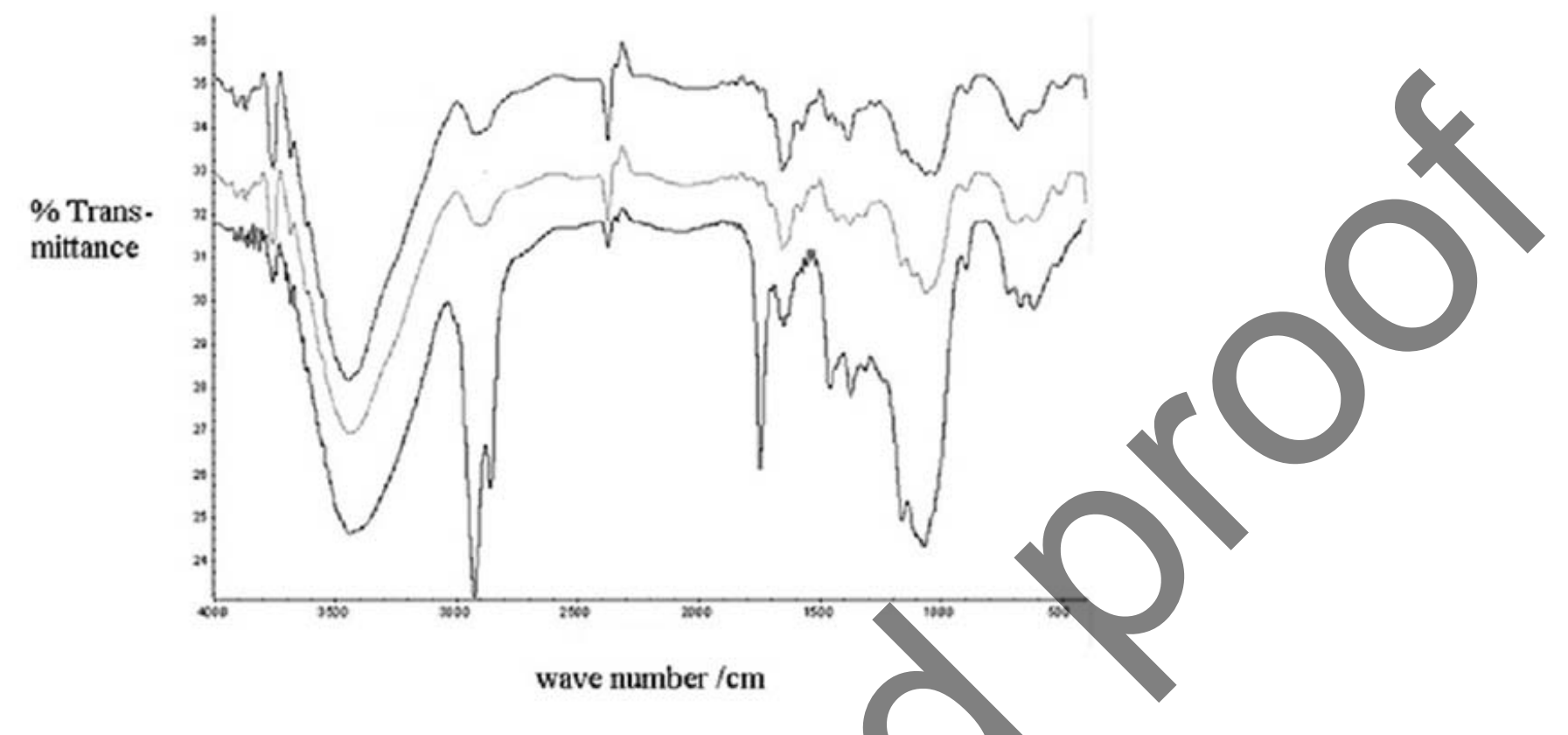

Figure 2

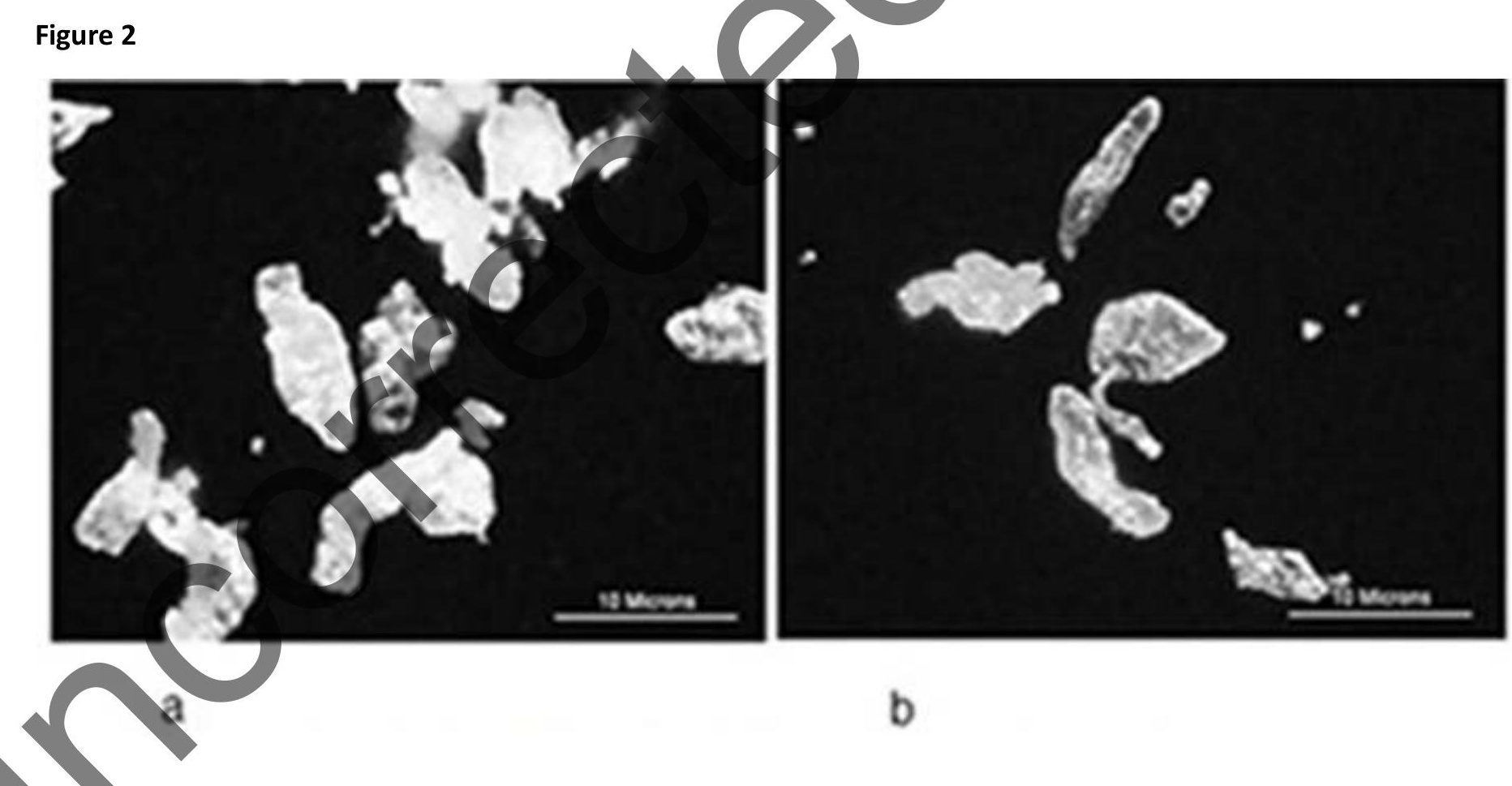


Figure 3

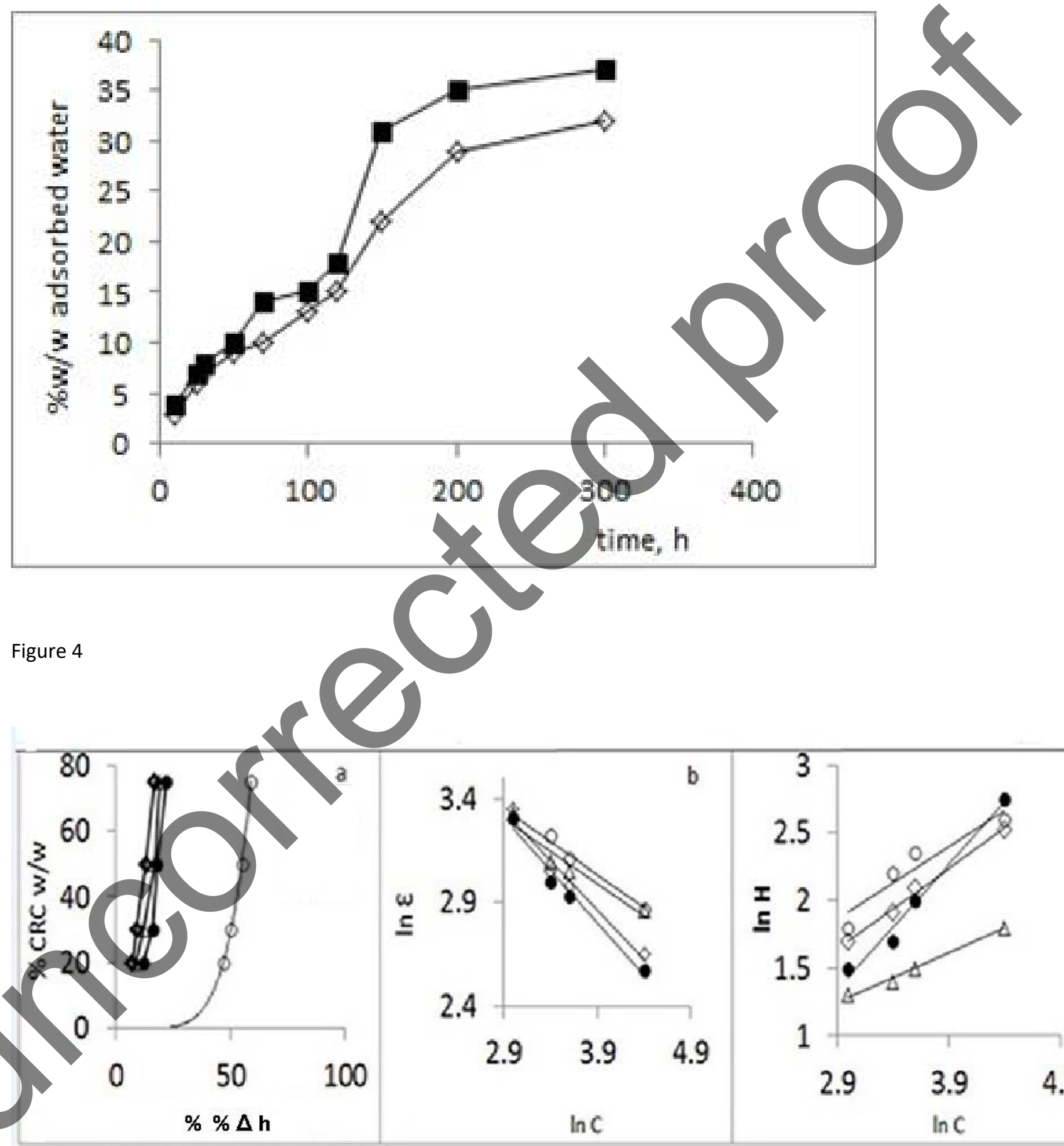


Figure 5

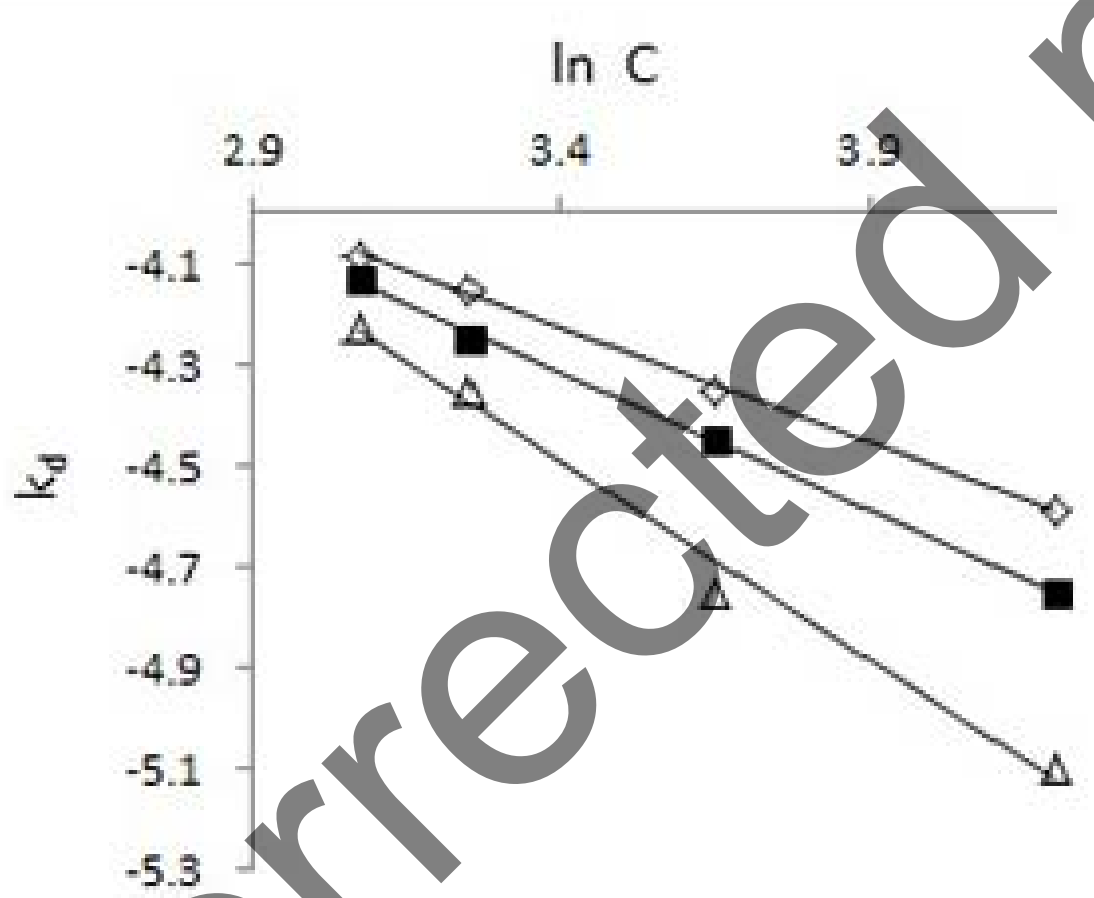


Figure 6

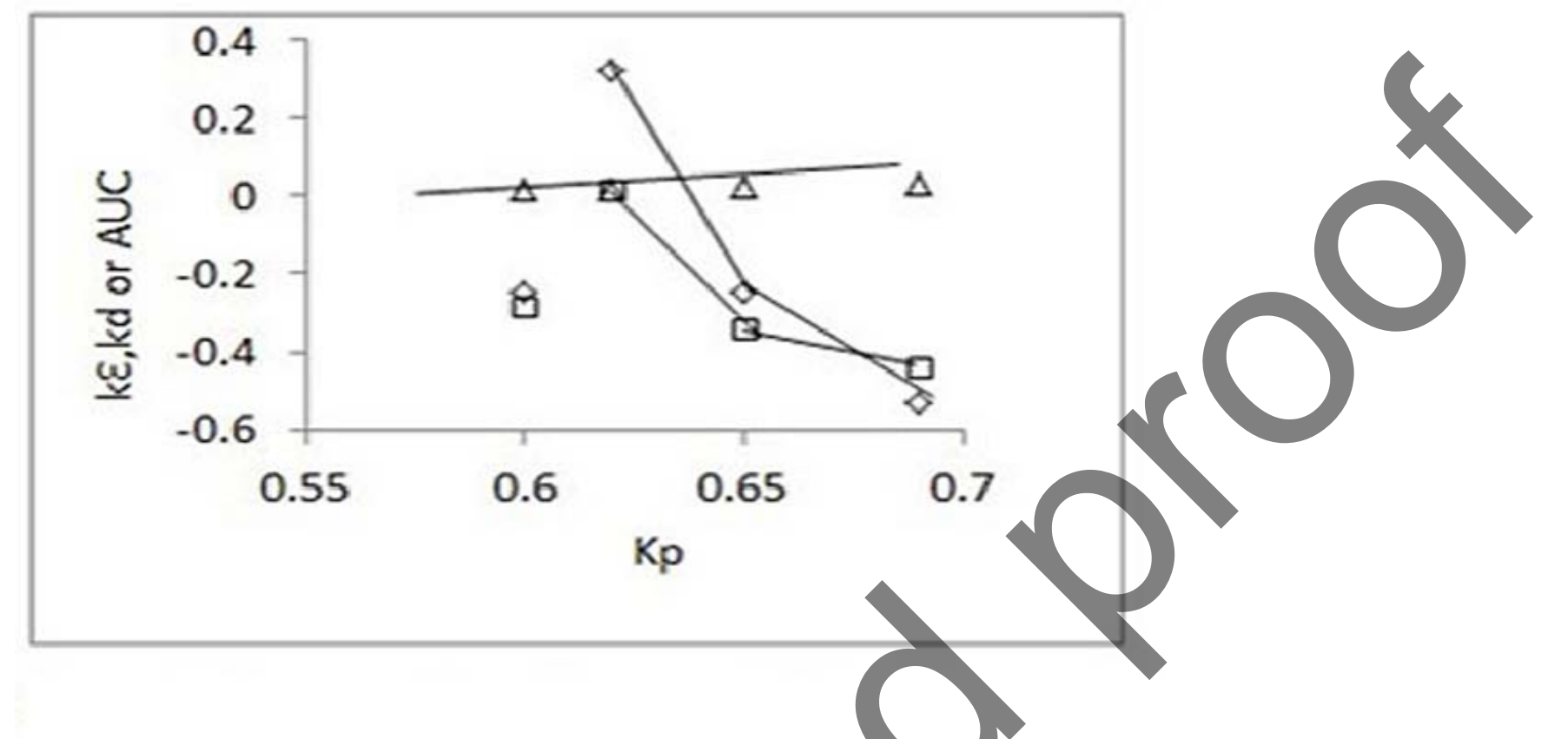

Figure 7

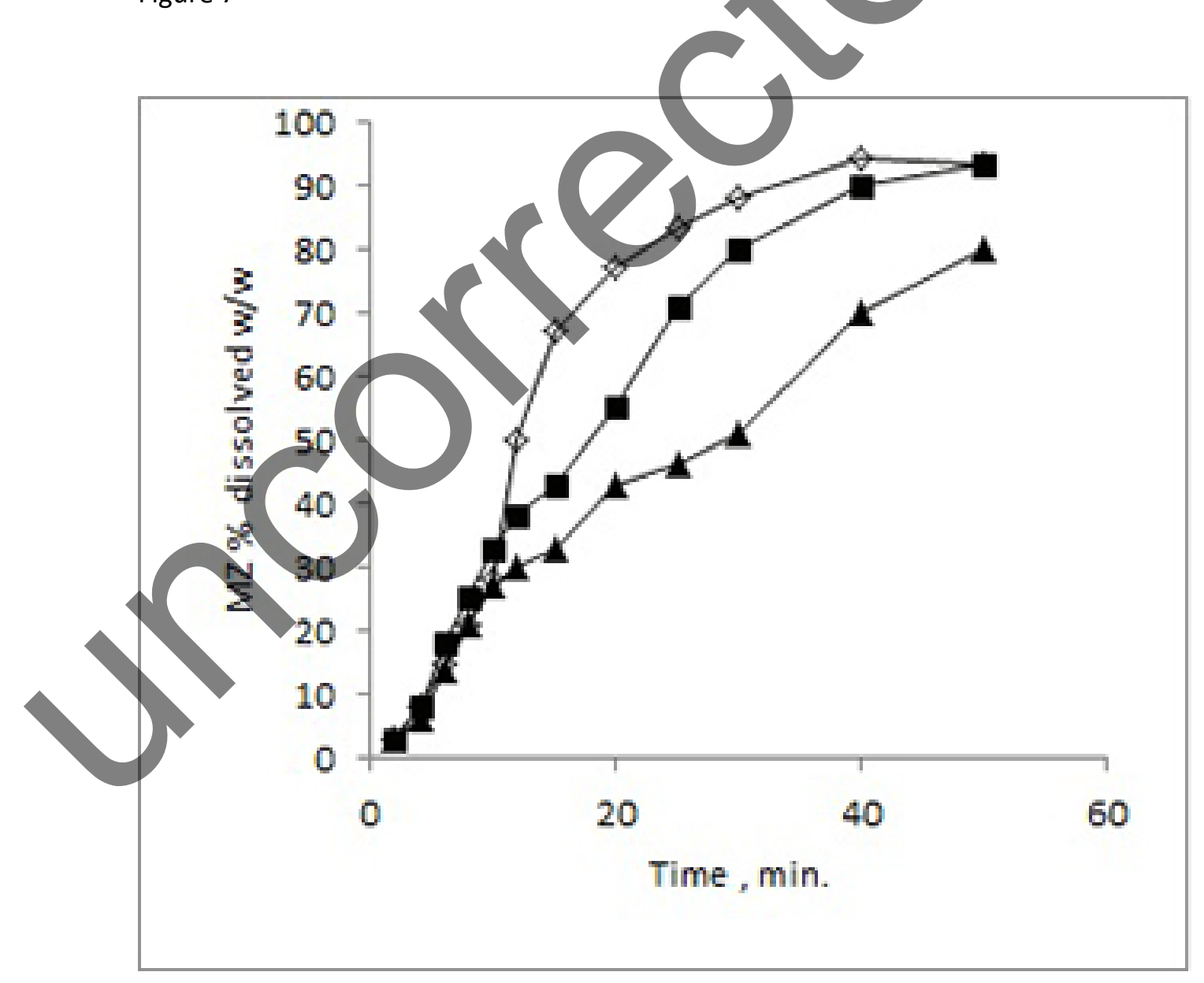

